\title{
COMPARISON OF PRISM IV AND PELOD 2 SCORE AS PREDICTOR OFMORTALITY IN CRITICALLY ILL CHILDREN IN ADAM MALIK GENERAL HOSPITAL
}

\author{
Thomas Silaban ${ }^{\mathrm{a}}$, Aridamuriany D Lubis ${ }^{\mathrm{b}}$, Bugis M Lubis ${ }^{\mathrm{c}}$ \\ a thomassilaban.ts@gmail.com \\ ${ }^{a}$ Pediatric Resident, Departement of Child Health, Faculty of Medicine, Universitas Sumatera Utara, Medan, Indonesia \\ ${ }^{\mathbf{b}}$ Emergency and Intensive Care Pediatric Consultant, Departement of Child Health, Faculty of Medicine, Universitas Sumatera Utara, Medan, \\ Indonesia

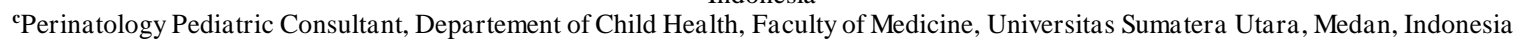

\begin{abstract}
Background: Critical illness is collection of conditions and disorders that have impact on the occurrence of organ dysfunction, prolonged morbidity and mortality. Score of mortality objectively calculates the severity of disease and predicts risk of mortality according to the clinical condition of patient. Today, no standardized scoring system that used in PICU for initial assessment of patients in Indonesia yet.

Objective: Comparing mortality's predictor ability between PRISM IV and PELOD 2 score as predictors of mortality in critically ill children at Haji Adam Malik General Hospital Medan.

Subject and Methods: Prospective cohort study was conducted in PICU of Haji Adam Malik General Hospital from September 2020 to March 2021. Characteristics of the sample were obtained through the medical record of patients treated in PICU. Assessment of PRISM IV and PELOD 2 score was carried out on the first and third days of patient being admitted in PICU.

Results: Of the 35 children who were treated, 15 (42.9\%) children were treated with respiratory problems. There were $18(51.4 \%)$ children died. It was found that there was no significant difference mean score of PRISM IV and PELOD 2 score on first and third days of examination ( $p>0.05$ ). It was also found that PRISM IV could predict mortality of children with critical illness on the first and third days (AUC 49.7\%; 57.2\%). PELOD 2 could predict mortality on first and third days (AUC 65.4\%; 69.3\%).

Conclusion: PRISM IV on the first and third days has lower accuracy than PELOD 2 in predicting mortality in critically ill children at Haji Adam Malik General Hospital Medan.
\end{abstract}

Keywords: critically ill children;PRISM IV;PELOD 2

\section{Introduction}

Critical illness is a collection of conditions and disorders that impact on organ dysfunction, prolonged morbidity and death. Another definition of critical illness is a variety of disease processes that cause physiological instability to the point of causing disability or death within minutes to hours. Patients admitted to Pediatric Intensive Care Unit (PICU) are considered critically ill patients (Watson et al, 2009)

Measurement of the severity of the disease when first admitted to PICU is very important to assess risk of mortality by calculating in scoring. Several scoring systems for predicting mortality in PICU include Pediatric Risk of Mortality (PRISM) and Pediatric Logistic Organ Dysfunction (PELOD) (Frost, 2007). Pediatric Risk of Mortality (PRISM) was developed from Physiological Stability Index (PSI) score measured by clinical assessment which is interpreted in the statistical results. PRISM consists of 14 variables with a rating range covering 6 human body systems. The PRISM assessment can be carried out when the patient is admitted to 
the intensive care room (first 24 hours) and then evaluated every 24 hours until the patient leaves the intensive care room. PRISM IV is the latest scoring that adds several variables, namely age, source of admission, cardiopulmonary arrest within 24 hours before admission, cancer, low risk system of primary dysfunction which includes dysfunction in the endocrine, hematologic, musculoskeletal and renal systems that are affected. The result summed with the scores that have been obtained from the neurologic and non-neurological subcategories in the PRISM III scoring. (Pollack et al, 2016)

The Pediatric Logistic Organ Dysfunction score is a descriptive scoring system used to determine the presence of organ dysfunction/failure, and the severity of illness in critically ill children. The PELOD 2 score is a revision and validation of the previous PELOD score. The PELOD score assessment includes the neurological, cardiovascular, renal, respiratory and hematologic systems. (Iskandar, 2008).

\section{Materials and Methods}

This study used prospective cohort study from October 2020 to March 2021. The sample was examined twice and conducted in PICU at RSUP Haji Adam Malik Medan. This study had permission from the Research Ethics Commission of the Universitas Sumatera Utara and RSUP Haji Adam Malik Medan.

This study examined 35 subjects in total. Patients were treated in the pediatric intensive care unit, aged 1 month to 18 years. Patient underwent surgery, malignancy, fulminant liver failure, acute renal failure, immunodeficiency, received transplantation were excluded from the study.

The datas were analyzed statistically with SPSS ( Statistical Product and Science Service) version 20. Univariate analysis to determine the frequency distribution of the research subject group proportions. Bivariate test was conducted to see relation between independent variables and dependent variables using comparison of the mean scores of PRISM IV and PELOD 2 scores in assessing mortality in critically ill children. $T$ paired test was used if data were normally distributed. Wilcoxon test was used if data were not normally distributed. The data were significant if the $\mathrm{p}$ value $<0.05$. The ability to distinguish between survival and non survival patient was performed by using Receiver Operating Characterisic (ROC) curve. (Dahlan, 2009). 


\section{Result}

This research was conducted at the Haji Adam Malik (HAM) General Hospital Medan, North Sumatra, from October 2020 to March 2021, with total sample of 35 children who met the inclusion criteria. Most of the child subjects were male, that is 17 children (48.6\%). The largest age group was children aged $<12$ months with total 10 people $(28.6 \%)$. Mostly, the indication for admitting to PICU was respiratory problem, that is 15 people (42.9\%). A total of 18 children $(51.4 \%)$ died. The initial characteristics of subjects can be seen in table 1 .

Table 1 Demographic Characteristics

\begin{tabular}{lc}
\hline Demographic Characteristics & $\mathbf{n}=\mathbf{3 5}$ \\
\hline Gender, n (\%) & $17(48.6)$ \\
Boy & $18(51.4)$ \\
Girl & \\
Age, n (\%) & $10(28.6)$ \\
$1-12$ months & $6(17.1)$ \\
$12-23$ months & $1(2.9)$ \\
$24-59$ months & $9(25.7)$ \\
$60-143$ months & $9(25.7)$ \\
144 months & \\
Indication, n (\%) & $15(42.9)$ \\
Respiration & $5(14.3)$ \\
KV & $10(28.6)$ \\
CNS & $1(2.9)$ \\
Shock & $4(11,4)$ \\
Kidney & \\
Ventilators, n $(\%)$ & $21(60)$ \\
Yes & $14(40)$ \\
Not & $10(7.42)$ \\
Length of stay, mean (SD), days & \\
Outcome, n $(\%)$ & $17(48.6)$ \\
Survive & $18(51.4)$ \\
Died & \\
\hline
\end{tabular}

Table 2 shows the PELOD 2 score and PRISM IV score on the first and third day by age group. There was no difference in PELOD 2 and PRISM IV scores between the first and third day of examination $(\mathrm{p}>0.05)$ in each age group. 
Table 2 PELOD 2 and PRISM IV Scores on Day One and Day Three by Age Group

\begin{tabular}{|c|c|c|c|c|c|}
\hline & $\begin{array}{c}1-12 \\
\text { months } \\
(\mathrm{n}=10)\end{array}$ & $\begin{array}{c}12-23 \\
\text { months } \\
(n=6)\end{array}$ & $\begin{array}{c}24-59 \\
\text { months } \\
(n=1)\end{array}$ & $\begin{array}{c}60-143 \\
\text { months } \\
(n=9)\end{array}$ & $\begin{array}{c}144 \\
\text { months } \\
(n=9)\end{array}$ \\
\hline \multicolumn{6}{|l|}{ First day } \\
\hline \multicolumn{6}{|l|}{ PELOD Score 2} \\
\hline Average (SD) & $3.3(2)$ & $7(1.55)$ & 6 & $3.67(1.8)$ & $6.44(5.86)$ \\
\hline Median (Min-Max) & $4(0-6)$ & $6.5(6-10)$ & & $4(1-6)$ & $5(1-19)$ \\
\hline \multicolumn{6}{|l|}{ PRISM IV } \\
\hline Average (SD) & $4.9(2.51)$ & $9.67(2.25)$ & 0 & $8.33(4.39)$ & $8.22(6.61)$ \\
\hline Median (Min-Max) & $5.5(0-8)$ & $9.5(6-12)$ & & $9(0-13)$ & $7(0-19)$ \\
\hline $\mathrm{p}$ & $0.125^{a}$ & 0.197 a & & $0.148^{\text {b }}$ & $0.772^{\text {ь }}$ \\
\hline \multicolumn{6}{|l|}{ The third day } \\
\hline \multicolumn{6}{|l|}{ PELOD Score 2} \\
\hline Average (SD) & $4.6(2.07)$ & $6(1,1)$ & 1 & $5(3.61)$ & $6(4)$ \\
\hline Median (Min-Max) & $5.5(0-6)$ & $6(4-7)$ & & $5(0-9)$ & $6(0-14)$ \\
\hline \multicolumn{6}{|l|}{ PRISM IV } \\
\hline Average (SD) & $5.3(2.41)$ & $8.83(0.98)$ & 2 & $7.22(5.29)$ & $8.11(4,4)$ \\
\hline Median (Min-Max) & $6(2-9)$ & $8.5(8-10)$ & & $10(0-13)$ & $7(3-18)$ \\
\hline $\mathrm{p}$ & 0.674 b & 0.414 a & & 0.458 a & 0.965 b \\
\hline
\end{tabular}

Wilcoxon, ${ }^{\text {bpaired T }}$

The results of the analysis using the ROC curve (figure 1) showed that the AUC of the PELOD 2 score on the first day of treatment in predicting mortality was $57.2 \%$ with $\mathrm{p}=0.468$ and $95 \% \mathrm{CI}$ $37.9 \%-76.5 \%$. 


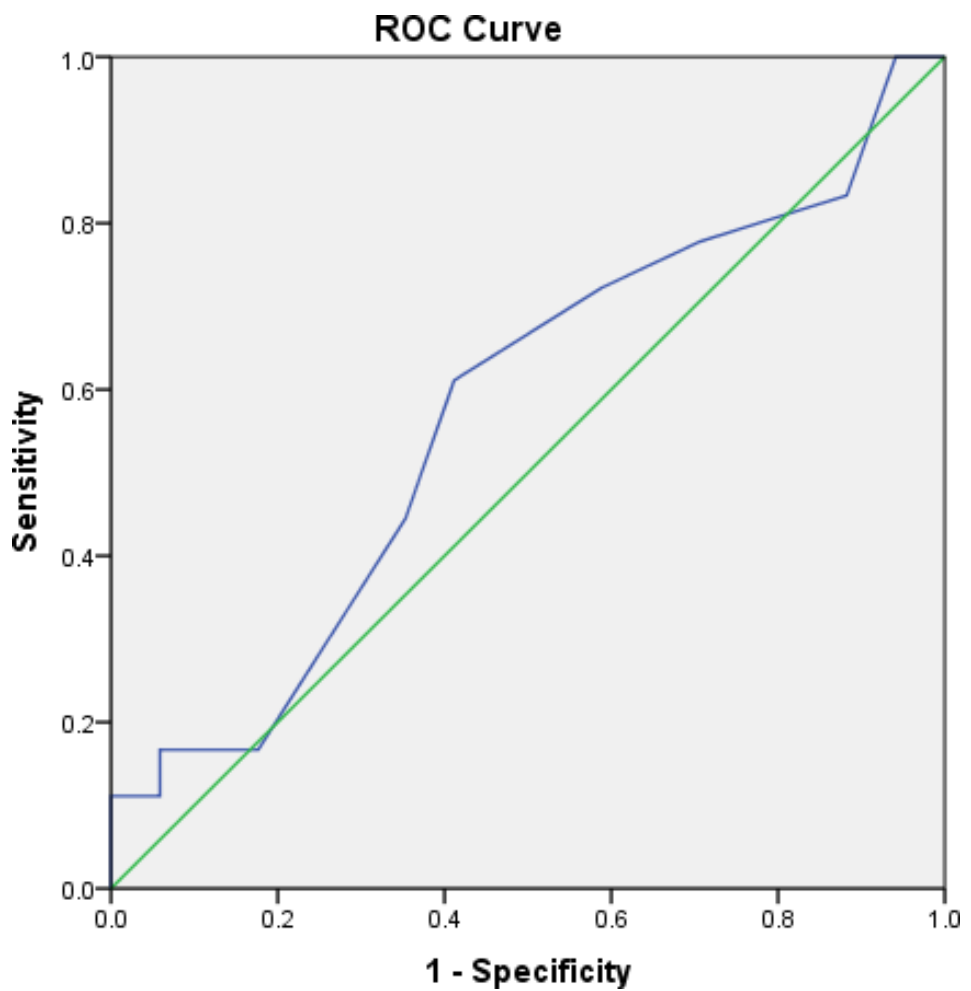

Figure 1 ROC Curve of PELOD 2 score on first day for Mortality

The results of the analysis using the ROC curve (figure 2) showed that the AUC of the PRISM IV score on the first day of examination in predicting mortality was $49.7 \%$ with $\mathrm{p}=0.974$ and $95 \%$ CI $30 \%-69.4 \%$ 


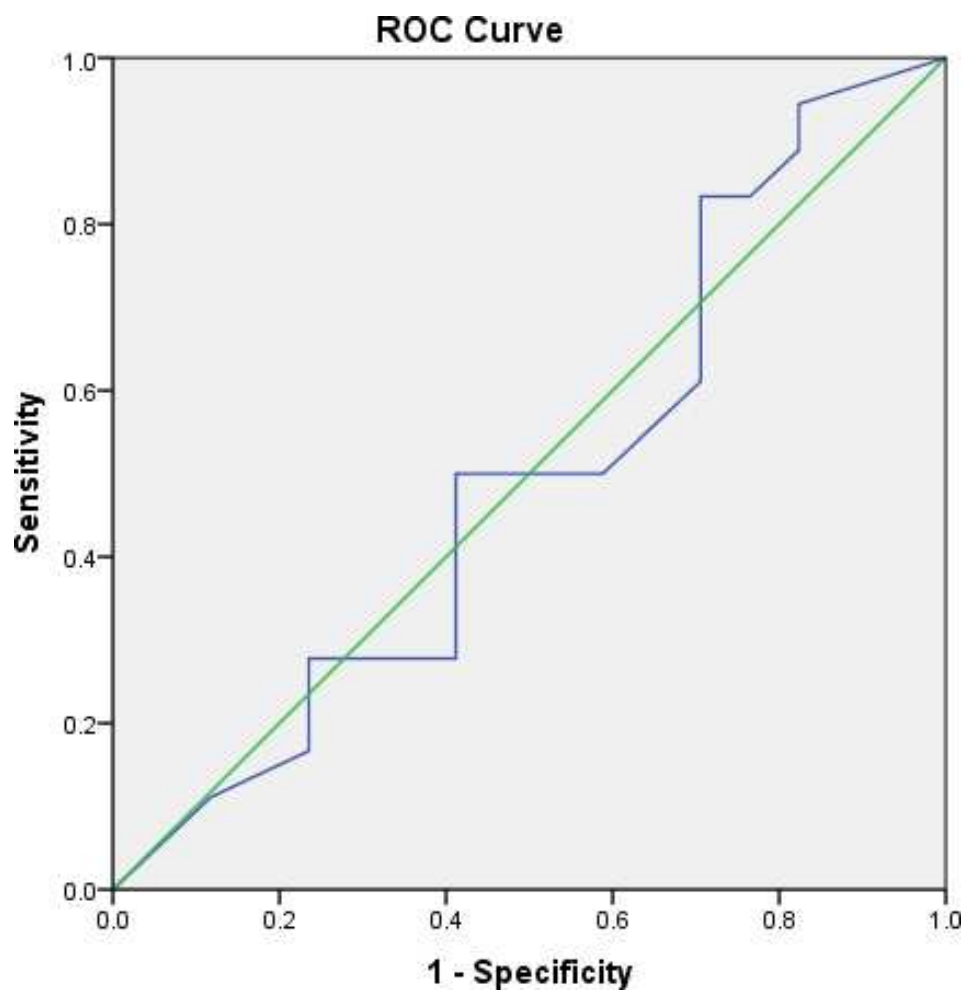

Figure 2 ROC Curve of PRISM IV on first day for Mortality

The results of the analysis using the ROC curve (figure 3) showed that the AUC of the PELOD 2 score on the third day of treatment in predicting mortality was $69.3 \%$ with $\mathrm{p}=0.051$ and $95 \% \mathrm{CI}$ $51.7 \%-86.9 \%$. 


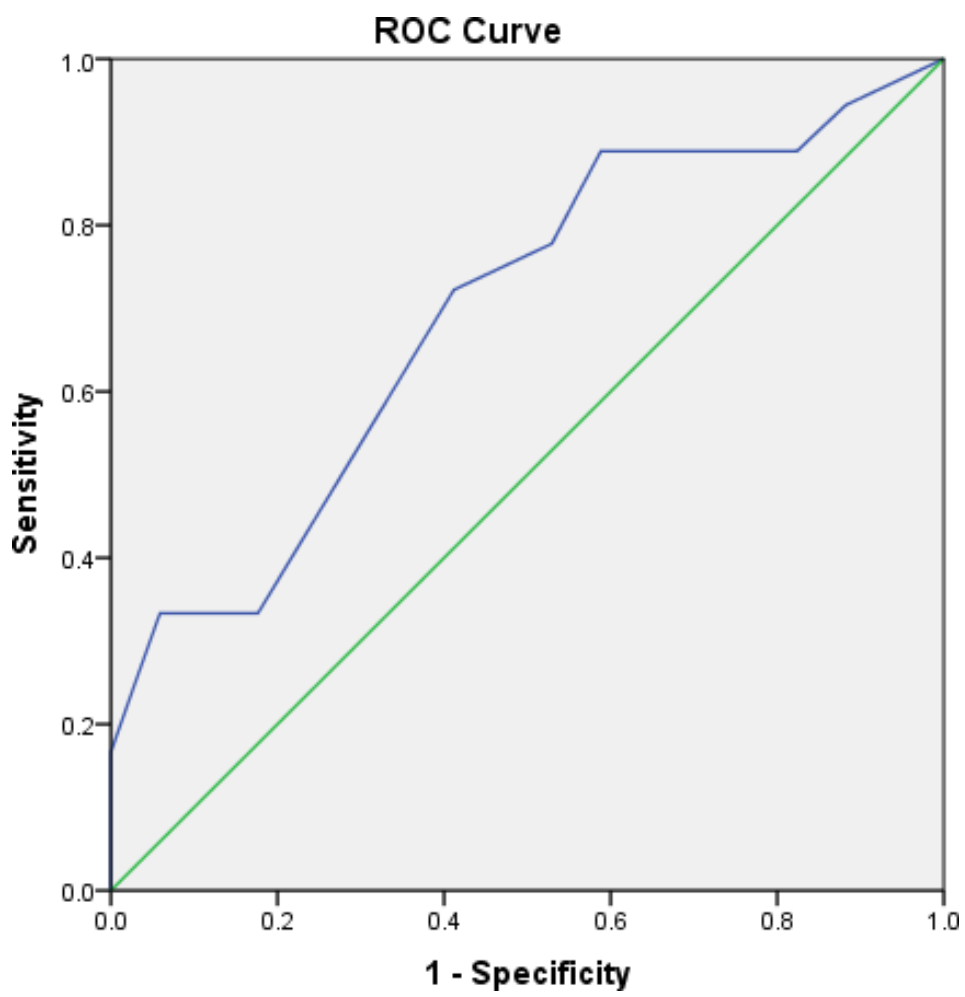

Figure 3 ROC Curve of PELOD 2 Score on third day for Mortality

The results of the analysis using the ROC curve (figure 4) showed that the AUC of the PRISM IV score on the third day of examination in predicting mortality was $65.4 \%$ with $p=0.121$ and $95 \%$ CI $47.1 \%-83.6 \%$. 


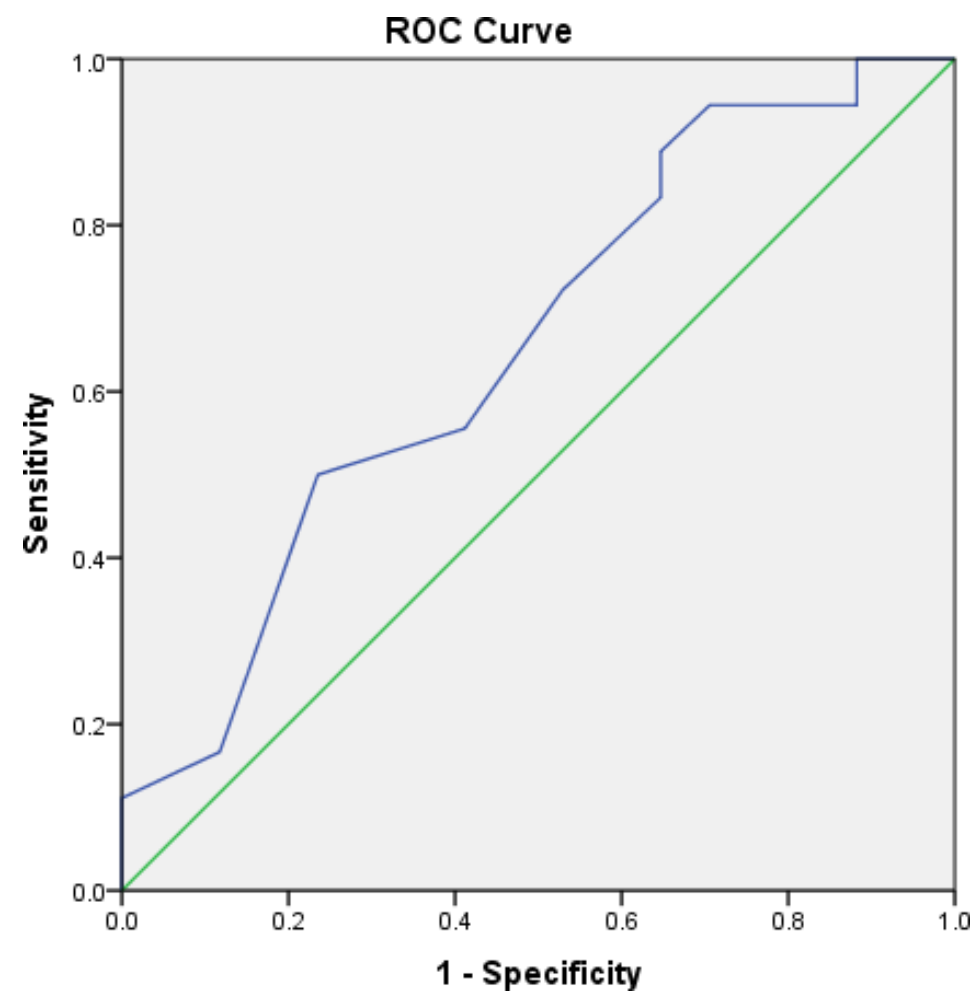

Figure 4 ROC Curve of PRISM IV on third day for Mortality

By using a cut off value of 7, the PELOD 2 score obtained from the first day of assessment in predicting mortality with sensitivity $83.3 \%$, specificity $17.6 \%$, Positive Predictive Value (PPV) of $51.7 \%$ and Negative Prediction Value (NPV) by 50\%. The accuracy of PELOD 2 score on the first day in predicting mortality was $51.4 \%$.

The third day assessment in predicting mortality with sensitivity $66.7 \%$, specificity $17.6 \%$, PPV of $46.2 \%$ and NPV of $33.3 \%$. The accuracy of the PELOD 2 score on the third day in predicting mortality was $42.9 \%$. 
Table 3. PELOD 2 Score Accuracy Value in Predicting Mortality

\begin{tabular}{lllllll}
\hline PELOD 2 & Die & Survive & Sensitivity & Specificity & NDP & NDN \\
\hline $\begin{array}{l}\text { The day I } \\
<7\end{array}$ & 15 & 14 & $83.3 \%$ & $17.6 \%$ & $51.7 \%$ & $50 \%$ \\
7 & 3 & 3 & & & & \\
$\begin{array}{l}\text { Day III } \\
<7\end{array}$ & 12 & 14 & $66.7 \%$ & $17.6 \%$ & $46.2 \%$ & $33.3 \%$ \\
7 & 6 & 3 & & & & \\
\hline
\end{tabular}

\section{Discussion}

The initial characteristic data in this study showed almost the same portion of sex between boy (48.6\%) and girl (51.4\%). Average length of stay of subjects in the study was 10 days. 18 children (51.4\%) died in this study. This study had the same result as another study conducted by Mianling et al, of 488 living patients, $311(63.7 \%)$ were boy and the median age was 8 (2-36) months, found 28 patients who died, $16(57,1 \%)$ were boys with a median age of $12(3-36)$ months. There were no significant differences in gender, age, site of infection or length of stay in PICU (Mianling et al,2019). Another study from Kumbar et al with ratio between boy and girl almost same showed no significant difference in gender for treating in PICU (Kumbar et al, 2020). The pattern of gender distribution recorded in this study almost same with recent study by Reshma RP et al, who reported there were not much different results regarding the sex distribution of patients admitted to the PICU with $48 \%$ girl and $52 \%$ boy did not have significant relation with mortality with p>0.05. (Rashma et al, 2019).

PRISM and PELOD score have been widely used to predict mortality. This is indicated by its performance in predicting with AUC value close to 1 . This result is different with this study. It was found that the PRISM IV score predicted mortality in critically ill children on the first day (AUC 49.7\%, $\mathrm{p}=0.974$ ) and third ( AUC 65.4\%, $\mathrm{p}=0.121$ ). In this study, it was also found that the PELOD 2 score was on the first day (AUC 57.2\%, $\mathrm{p}=0.468$ ) and the third day (AUC 69.3\%, $\mathrm{p}=0.051)$. Research in China states that the performance of these two predictors is less than ideal compared to previous studies. One of them is due to differences in the character of the research 
subjects. In that study, more than half of the study subjects were admitted to the PICU with indications of respiratory problems which showed a greater difference in the number of patient characteristics than the characteristics of patients in Western countries. Many of these respiratory problems were diagnosed with severe pneumonia accompanied by other diseases such as heart disease, neuromuscular disease with more complex management. In addition, the use of broadspectrum antibiotics to control bacterial infections can increase the risk of bacterial resistance which can affect mortality rates. The research that we did was the same as the research in China where the most indications of respiratory problems (42.9\%). Another thing that can make this difference was the disparity in the quality of services in the pediatric intensive care unit and the facilities available in the pediatric intensive care unit, which are definitely inferior from the facilities in Western countries. (Zhang, 2020).

In line with the Chinese study, a cohort study in Pakistan also compared the 3 predictors (PRISM, PELOD, and PIM) conducted in the pediatric intensive care unit in Lahore and concluded that PELOD had poor performance compared to PRISM and PIM. Several things that can cause this was limited hospital facilities in developing countries and due to a poor medical service system. (Qureshi, 2007). Another thing that was obtained from a meta-analysis of mortality predictors between PRISM IV, PIM-3 and PELOD 2 stated that these three predictors had a good performance in predicting mortality in pediatric intensive care units but with low and moderate certainty of evidence.

An Austrian hospital study compared predictors of mortality among septic patients admitted to a pediatric intensive care unit. From the results of this study, it was found that PIM, PRISM III and PELOD 2 were good predictor scores of mortality. In septic patients, PELOD 2 and PRISM IV were better predictors of mortality than other mortality predictors. PELOD 2 score as the best predictor of mortality compared to other predictors when used repeatedly. (Niederwanger, 2018)

In this study, the PELOD 2 score was obtained using a cut off value of 7 , the $\mathrm{p}$ value $=$ 0.046. PELOD 2 score on the first day to predict mortality with a sensitivity value of $83.3 \%$, 
specificity 17.6\%, Positive Predictive Value (NDP) 51.7\% and Negative Prediction Value (NDN) of $50 \%$. The accuracy of the PELOD 2 score on the first day in predicting mortality was 51.4\%. The PELOD 2 score from the third day of assessment in predicting mortality with a sensitivity value of $66.7 \%$, specificity of $17.6 \%$, NDP value of $46.2 \%$ and NDN of $33.3 \%$. The accuracy of the PELOD 2 score on the third day in predicting mortality was $42.9 \%$. Research at Haji Adam Malik Hospital which examined the use of PELOD 2 scores, C reactive protein and procalcitonin as predictors of mortality in septic patients gave different results. Of the 79 children studied with a mortality rate of $55.7 \%$, it was found that the PELOD 2 score with a cut off of 7 (OR: 3.47 (95\% CI: 1.68-7.19) could be a predictor of mortality for patients admitted to the pediatric intensive room (Lubis et al, 2020).

This study has advantages, this was the first study conducted at Haji Adam Malik General Hospital to compare the values of PRISM IV and PELOD 2 in critically ill children. However, this research still has limitations. First of all, the comparison of PELOD-2 with other measurement standards to assess organ dysfunction such as SOFA, PIM and others was not conducted, resulting in a lack of variation in the comparison data. Second, this study did not compare mortality caused by sepsis, the relationship between mortality and nutritional status in patients, and the use of ventilators used during PICU care.

\section{Conclusion}

PRISM IV on the first and third days has lower accuracy than PELOD 2 in predicting mortality in critically ill children at Haji Adam Malik General Hospital Medan.

\section{Conflict of interest}

The authors declare that there are no conflicts of interest

\section{References}


Dahlan M. Statistics for Medicine and Health . 6th ed.; 2009.

Iskandar HR, Mulyo D, Agnes P, Suryatin Y. Comparison of pediatric logistic organ dysfunction (PELOD) score and pediatric risk of mortality (PRISM III) as mortality predictor in patients with dengue shock syndrome. Pediatric 2008: suppl 121:129.

Kumbar S, Chandrashekhara. Assessment of pSOFA-L score in predicting the clinical outcome of critically ill children. Int J Contemp Pediatr. 2020;7(4):925-31.

Lubis M, Lubis AD, Nasution BB. The usefulness of c-reactive protein, procalcitonin, and pelod 2 score as a predictive factor of mortality in sepsis. The Indonesian Biomedical Journal.2020;2(12): 102-8.

Mianling Z, Yuge H, Tufeng I, Lu X, Ting T, Miaofen L et al. Performance of the Pediatric Sequential Organ Failure Assessment Score in assessing the prognosis of children with sepsis in PICU of a developing country: a single-center retrospective observational study. Iran J Pediatr. 2019;29(5):1-6.

Niederwanger C, Varga T, Hell T, Stuerzel D, Prem J, Gassner M et al. Comparison of pediatric scoring systems for mortality in septic patients and the impact of missing information on their predictive power: a retrospective analysis. International Journal of Contemporary Medical Research. 2018;9(5): 16-8.

Pollack MM, Holubkov R, Funai T, et al. The pediatric risk of mortality score: update 2015. Pediatric critical care medicine: a journal of the Society of Critical Care Medicine and the World Federation of Pediatric Intensive and Critical Care Societies. 2016; 17 (1):2.

Qureshi AU, Ali AS, Ahmad M. Comparison of three prognostic scores (PRISM, PELOD and PIM 2) at pediatric intensive care unit under Pakistani circumtances. J Ayub Med Coll Abbottabad. 2007;19(2):49-53.

Rashma RP, Remya S, Jayakumar C, Shanavas M, Manu R. Mortality Profile of children admitted to intensive care unit of a tertiary care hospital in Kerala, South India. Int $\mathrm{J}$ Med Clin Sci. 2018;1(1):13-6.

Watson RS, Hartman ME. Epidemiology of critical illness. Science and Practice of Pediatric Critical Care Medicine. 2009;12:29-33.

Zhang Z, Huang X, Wang Y, Li Y, Miao H, Zang C et al. Performance of three mortality prediction scores and evaluation of important determinants in eight pediatric intensive care units in China. Frontiers in Pediatrics.2020;8:1-8. 